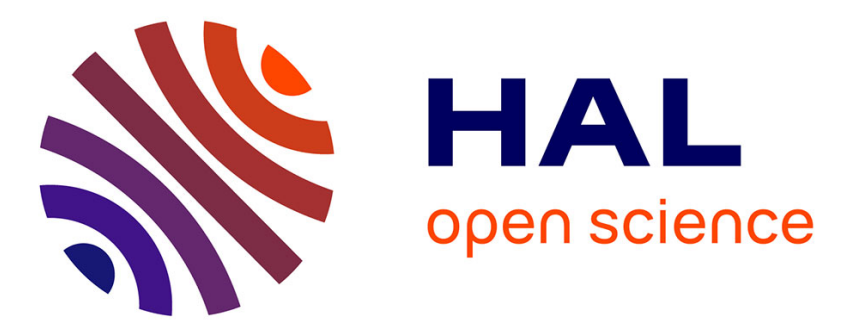

\title{
A new approach to assess isostatic compensation of topography in continental domain from GOCE gravity gradients
}

Cecilia Cadio, Anita Saraswati, Rodolphe Cattin, Stephane Mazzotti

\section{- To cite this version:}

Cecilia Cadio, Anita Saraswati, Rodolphe Cattin, Stephane Mazzotti. A new approach to assess isostatic compensation of topography in continental domain from GOCE gravity gradients. Geophysical Journal International, 2016, 207 (2), pp.645-654. 10.1093/gji/ggw281 . hal-01467540

\author{
HAL Id: hal-01467540 \\ https://hal.science/hal-01467540
}

Submitted on 17 Feb 2017

HAL is a multi-disciplinary open access archive for the deposit and dissemination of scientific research documents, whether they are published or not. The documents may come from teaching and research institutions in France or abroad, or from public or private research centers.
L'archive ouverte pluridisciplinaire HAL, est destinée au dépôt et à la diffusion de documents scientifiques de niveau recherche, publiés ou non, émanant des établissements d'enseignement et de recherche français ou étrangers, des laboratoires publics ou privés. 


\title{
A new approach to assess isostatic compensation of topography in continental domain from GOCE gravity gradients
}

\author{
Cécilia Cadio, ${ }^{1}$ Anita Saraswati, ${ }^{1}$ Rodolphe Cattin ${ }^{1}$ and Stéphane Mazzotti ${ }^{1,2}$ \\ ${ }^{1}$ Géosciences Montpellier, Université de Montpellier and CNRS UMR 5243, CC060 Place E. Bataillon, F-34095 Montpellier Cedex 05, France. \\ E-mail: cecilia.cadio@gm.univ-montp2.fr \\ ${ }^{2}$ School of Earth and Ocean Sciences, University of Victoria, PO Box 3065 STN CSC, Victoria, BC V8W3V6, Canada
}

Accepted 2016 July 25. Received 2016 July 21; in original form 2016 January 26

\begin{abstract}
S UMMAR Y
Estimating how topography is maintained provides insights into the different factors responsible for surface deformations and their relative roles. Here, we develop a new and simple approach to assess the degree of isostatic compensation of continental topography at regional scale from GOCE gravity gradients. We calculate the ratio between the radial gradient observed by GOCE and that calculated from topography only. From analytical and statistical formulations, simple relationships between this ratio and the degree of compensation are obtained under the Airy-Heiskanen isostasy hypothesis. Then, a value of degree of compensation at each point of study area can be easily deduced. We apply our method to the Alaska-Canada Cordillera and validate our results by comparison with a standard isostatic gravity anomaly model and additional geophysical information for this area. Both our GOCE-based results and the isostatic anomaly show that Airy-Heiskanen isostasy prevails for the Yukon Plateau whereas additional mechanisms are required to support topography below the Northwest Territories Craton and the Yakutat collision zone.
\end{abstract}

Key words: Numerical approximations and analysis; Satellite geodesy; Gravity anomalies and Earth structure; Continental margins: convergent; North America.

\section{INTRODUCTION}

An important question in geodynamics, especially for continental domains, is to distinguish the part of the topographic signal isostatically compensated by either crustal roots (Airy-Heiskanen model) or lateral density variations (Pratt-Hayford model) from the one associated with lithosphere rigidity (Vening-Meinesz model; Watts 2001) and present-day mantle convection (Braun 2010; Flament et al. 2013). Topography variations are associated with gravity anomalies for which the amplitude is not only related to mass anomalies at the surface but also to compensating masses at depth. Indeed, the spatial variations of gravity are directly related to the density anomalies located in both the crust and mantle. Joint analysis of topography and gravity data can thus help identify the isostatic component from the dynamic one in the topographic signal, and gives an estimate of their contribution (Hager et al. 1985; Watts 2001; Cadio et al. 2012).

Owing to space gravity missions, unprecedented high-quality data are now available on the entire Earth surface and improve considerably our knowledge of gravity field (Tapley et al. 2005). In particular, the GOCE mission (Gravity Field and Steady-State Ocean Circulation Explorer; Drinkwater et al. 2003) allows the study of features as small as $80 \mathrm{~km}$ in continental orogens (Hirt et al. 2012; Bruinsma et al. 2014), often characterized by a sparse spatial coverage of available ground gravity data due to high reliefs. Such resolution is made possible by the low altitude $(\sim 255 \mathrm{~km})$ of the GOCE satellite, which does not provide measurements of the gravity field but of its variations in the three spatial directions (Rummel et al. 2011). Beyond the resolution improvement compared to previous space gravity missions, GOCE gravity gradients are also much more sensitive to the spatial structure and directional properties of the attracting masses than classical observation of gravitational intensity (Mikhailov et al. 2007).

These satellite gravity gradients constitute a new class of observations that requires the development of new methods in order to extract information. In solid Earth geophysics, analyses of GOCE gravity gradients have been mainly developed to address the global Earth's internal structure at crustal (Reguzzoni et al. 2013), lithospheric (Bouman et al. 2015) and mantle (Panet et al. 2014) level. At a regional scale, GOCE gravity data have been used to identify geological structures (Álvarez et al. 2012; Mariani et al. 2013; Shin et al. 2015).

Here, we propose a new and simple approach to assess the mechanism and degree of isostatic compensation in a given region using GOCE gravity gradients. We use analytical and statistical formulations to compute the degree of topography compensation under the Airy-Heiskanen isostasy hypothesis. This allows identifying areas for which this hypothesis is valid and those requiring different or additional compensation mechanisms. Thus, our approach provides complementary information to usual analysis of the geoid to 


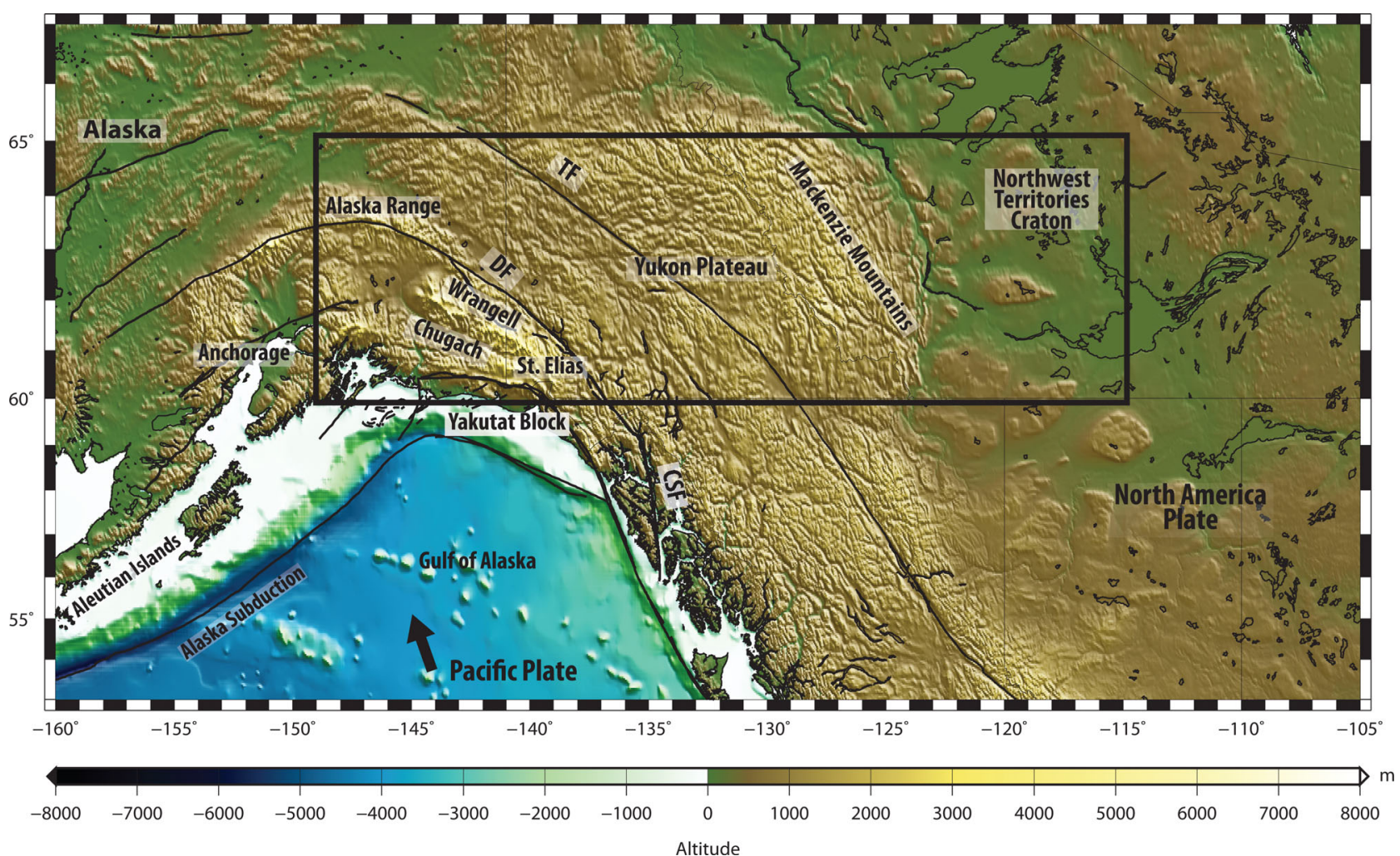

Figure 1. Topography of the NW American cordillera. Thin black lines show some of the primary faults for reference (DF, Denali Fault and TF, Tintina Fault). The arrow indicates the motion of the Pacific Plate relative to North America. The black box marks the study area.

elevation ratio used to estimate the apparent compensation depth of a specific topographic structure (Chase et al. 2002; Cadio et al. 2012). Also, on continental areas, the gravity gradients measured from the GOCE satellite provide a homogeneous coverage of higher resolution than previously available gravity data. This improvement in resolution is in part related to the technique of differentiation. GOCE gravity gradients are thus better suited to study continental structures at the regional scale. Beyond this benefit, the new approach allows us to interpret a new kind of data defined in different spatial directions. Although we focus on the radial gravity gradient in this study, our method can constitute a basis to explore the others components.

We test our method over the NW America orogen (Fig. 1), which is associated with the accretion of allochthonous blocks carried by the Pacific plate in the corner of the Gulf of Alaska (e.g. Lahr \& Plafker 1980; Plafker et al. 1994). The study area extends from the Yakutat collision zone along the continental margin to the Canadian Craton, spanning the entire Alaska-Canada Cordillera. The topography pattern, the crustal thickness and the isostatic compensation mode are well defined in most of this region and vary significantly (Lewis et al. 2003; Hasterok \& Chapman 2007; Mazzotti et al. 2008), making this area particularly well adapted to validate our method.

In the following, we present our approach to estimate the degree of the local isostatic compensation of the topography in continental domains at regional scale. First, we explain the methodology from which the degree of compensation is deduced. We introduce the GOCE gravity gradients and present the formulations obtained for a synthetic model. Next, we apply our approach to the NW America orogeny. Finally, we discuss the results in terms of isostatic and dynamic topography in the region.

\section{METHODS}

In our approach, the degree of compensation $\alpha$ is estimated from GOCE measurements. First, we calculate the ratio $\beta$ between the radial gradient observed by GOCE and that modeled from topographic contribution only. Next, using a simple cylinder model, we obtain a relationship between $\alpha$ and $\beta$ under the Airy-Heiskanen isostasy hypothesis. In this way, a degree of compensation can be deduced at each point of the study area.

\subsection{GOCE and topography gravity gradients}

The European Space Agency's GOCE mission provides data with unprecedented global resolution (Bruinsma et al. 2014). GOCE directly measures, on a $\sim 255-\mathrm{km}$-altitude orbit, the six components of the Earth's gravity gradient tensor $\left(T_{x x}, T_{y y}, T_{z z}, T_{x y}, T_{y z}, T_{z x}\right)$ corresponding to the first spatial derivatives of the gravity in three directions (Rummel et al. 2011):

$T_{i j}=\frac{\partial g_{i}}{\partial j}=\frac{\partial g_{j}}{\partial i}=T_{j i}$.

The GOCE High-level Processing Facility (Fuchs \& Bouman 2011) expresses the gradients in the Local North Oriented Frame (LNOF). In this right-handed North-West-Up frame, the radial gradient $T_{z z}$ gives an isotropic view of masses whereas the others derivatives underline masses orthogonal to the differentiation directions.

In this study, we use the gravity gradient grid at $255 \mathrm{~km}$ above the WGS 84 reference ellipsoid established by Bouman et al. (2016). The gradients are given in the LNOF frame with a resolution of 0.2 deg. The grid combines the GOCE gradients measured during the period from 2010 February 1 to 2013 November 11 for the small and intermediate scales $(<700 \mathrm{~km}$ ) and GRACE (Gravity Recovery 


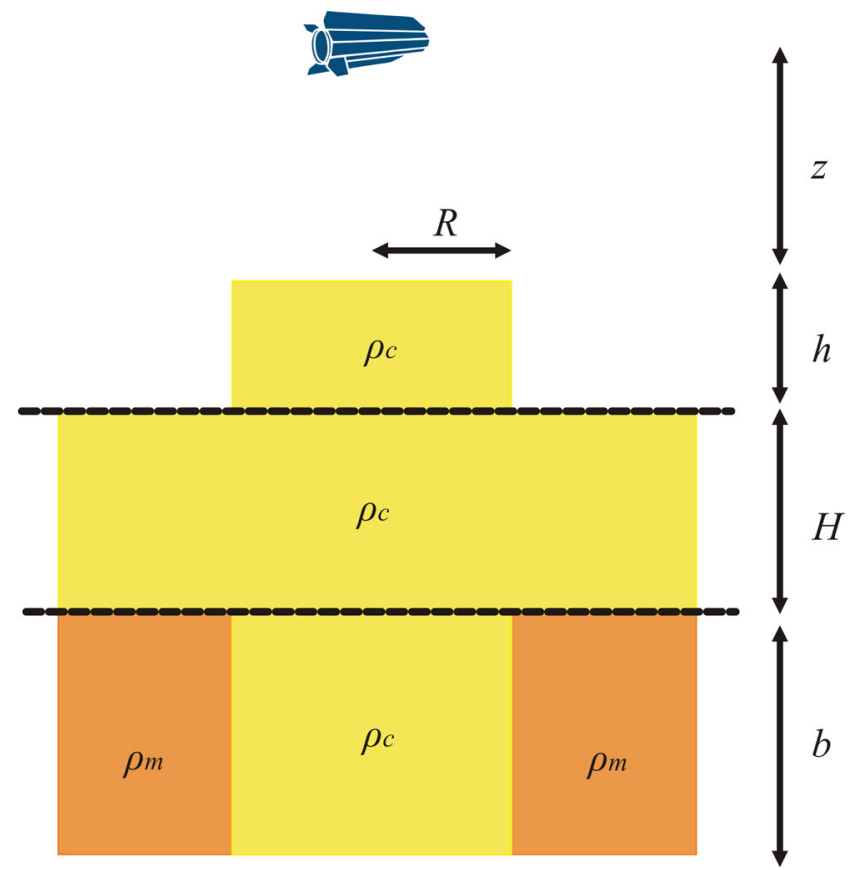

Figure 2. Cylinder model of the topography with its compensation following the Airy-Heiskanen isostatic model with $R$, the radius of the cylinder, $h$ the elevation, $H$ the hydrostatic equilibrium crustal thickness, $b$ the thickness of the crustal root, $\rho_{c}$ the crustal density and $\rho_{m}$ the mantle density. The satellite is at altitude $z+h=255 \mathrm{~km}$ above the ellipsoid.

and Climate Experiment) data for longer wavelengths. Based on satellite data only, it therefore provides a precision over the whole Earth of 0.01-0.06 E (Eötvös, with $1 \mathrm{E}=10^{-9} \mathrm{~s}^{-2}$ ) for the $T_{z z}$ component (Panet et al. 2014). In the following, we consider the signal as significant when its amplitude is above $0.05 \mathrm{E}$.

The gravity gradient due to topography is given by the GeoExplore project (Grombein et al. 2013, 2014; Bouman et al. 2016). The topographic contribution is estimated from the spherical harmonic model RWI_TOPO_2012, complete to degree and order 1800 (Grombein et al. 2014). In this model, the DTM2006.0 topography (Pavlis et al. 2007) is decomposed into three layers corresponding to rock, water and ice masses with density values of 2670, 1000 and $920 \mathrm{~kg} \mathrm{~m}^{-3}$, respectively.

\subsection{Synthetic model}

\subsubsection{Model parameters}

We evaluate the contribution of a partially or totally compensated topography in the radial component of the gravity gradient tensor from synthetic models. We assume a local isostatic compensation following the Airy-Heiskanen model in which the topography is accommodated by variations in Moho depth, the crust having a constant density (Fig. 2). The gravitational signal of a compensated topography is thus related to both the topographic mass excess and the crustal root mass deficit. In order to derive simple analytical expressions, we approximate a given topography and the associated crustal root as a superimposition of two cylinders separated by a distance $H$ corresponding to a reference crust (Fig. 2). Parameters of this model correspond to the cylinder density, height and radius. The density value is the crustal density $\rho_{c}$ for the topography and the crust-mantle density contrast $\Delta \rho=\rho_{c}-\rho_{m}$ for the root.
The thickness $b$ of the root is calculated from the height $h$ of the topography:

$b=-\alpha \frac{\rho_{c}}{\Delta \rho} h$,

where $\alpha$ is the degree of compensation. For $\alpha=1$, the topography is totally compensated in the Airy-Heiskanen hypothesis, whereas $\alpha>1$ and $\alpha<1$ are associated with an over- and undercompensated topography, respectively. The two cylinders having the same radius $R$, a model is thus described by a set of six independent parameters: $\left(\alpha, \rho_{c}, \Delta \rho, h, R, H\right)$.

\subsubsection{Gravity and gravity gradient}

The vertical component of the gravitational attraction $\Delta g$ due to the two-cylinder model can be analytically calculated above the centre of the cylinder as (e.g. Turcotte \& Schubert 2002):

$\Delta g=\Delta g_{\text {topo }}+\Delta g_{\text {crustal root }}$

where

$$
\begin{aligned}
& \Delta g_{\text {topo }}=2 \pi G \rho_{c}\left(h+\sqrt{z^{2}+R^{2}}-\sqrt{(z+h)^{2}+R^{2}}\right) \\
& \Delta g_{\text {crustal root }}=2 \pi G \Delta \rho \\
& \quad \times\left(b+\sqrt{(z+h+H)^{2}+R^{2}}-\sqrt{(z+h+H+b)^{2}+R^{2}}\right)
\end{aligned}
$$

with $G$ the gravitational constant (Table 1) and $z$ the distance above the upper surface of the topography cylinder (Fig. 2). Here, to be consistent with GOCE data, the measurement point is held at altitude $z+h=255 \mathrm{~km}$ above the ellipsoid.

As the GOCE gravity gradient is the first vertical derivative of $\Delta g$, the analytical radial component $T_{z z}$ is derived from eqs (3) and (4):

$\mathrm{T}_{\mathrm{zz}}=\frac{\partial \Delta g}{\partial z}=\frac{\partial \Delta g_{\text {topo }}}{\partial z}+\frac{\partial \Delta g_{\text {crustal root }}}{\partial z}=T_{z z_{\text {topo }}}+T_{z z_{\text {crustal root }}}$

where

$$
\begin{aligned}
T_{z z_{\text {topo }}}= & 2 \pi G \rho_{c}\left(\frac{z}{\sqrt{z^{2}+R^{2}}}-\frac{z+h}{\sqrt{(z+h)^{2}+R^{2}}}\right) \\
T_{z z_{\text {crustal root }}=} & 2 \pi G \Delta \rho\left(\frac{z+h+H}{\sqrt{(z+h+H)^{2}+R^{2}}}\right. \\
& \left.-\frac{z+h+H+b}{\sqrt{(z+h+H+b)^{2}+R^{2}}}\right) .
\end{aligned}
$$

The ratio $\beta$ between the total gradient $T_{z z}$ and the topography gradient $T_{z z_{\text {topo }}}$ is:

$\beta=\frac{T_{z z}}{T_{z z_{\text {topo }}}}=\frac{T_{z z_{\text {topo }}}+T_{z z_{\text {crustal root }}}}{T_{z z_{\text {topo }}}}=1+\frac{T_{z z_{\text {crustal root }}}}{T_{z z_{\text {topo }}}}$.

\subsubsection{Relationships between $\alpha$ and $\beta$}

In order to derive a relationship between the degree of compensation $(\alpha)$ and the total to topography gradient ratio $(\beta)$, we assume a priori information on $\rho_{c}, \Delta \rho, h, R$ and $H$, with value ranges that 
Table 1. Definitions of parameters and their values. The ranges for the Alaska-Canada Cordillera are in italic. $\alpha_{\min }$ and $\alpha_{\max }$ are the upper and lower bounds of the reference model in Fig. 3.

\begin{tabular}{lll}
\hline Parameters & Definition & Value and range \\
\hline$G$ & Gravitational constant & $6.67 \times 10^{-11} \mathrm{~m}^{3} \mathrm{~kg}^{-1} \mathrm{~s}^{-2}$ \\
$\rho_{c}$ & Crustal density & $2600-2900 \mathrm{~kg} \mathrm{~m}^{-3}$ \\
$\rho_{c \_ \text {max }}$ & Highest value for $\alpha_{\max }$ & $2900 \mathrm{~kg} \mathrm{~m}^{-3}$ \\
$\Delta \rho$ & Crust-mantle density contrast & $-700-300 \mathrm{~kg} \mathrm{~m}^{-3}$ \\
$\left|\Delta \rho_{\max }\right|$ & Highest value for $\alpha_{\max }$ & $-700 \mathrm{~kg} \mathrm{~m}^{-3}$ \\
$h$ & Elevation & $10-4.5 \times 10^{3} \mathrm{~m}$ \\
$h_{\min }$ & Lowest value for $\alpha_{\min }$ & $10 \mathrm{~m}$ \\
$h_{\max }$ & Highest value for $\alpha_{\max }$ & $4.5 \times 10^{3} \mathrm{~m}$ \\
$R$ & Cylinder radius & $1-500 \times 10^{3} \mathrm{~m}$ \\
$R_{\min }$ & Lowest value for $\alpha_{\max }$ & $1 \times 10^{3} \mathrm{~m}$ \\
$R_{\max }$ & Highest value for $\alpha_{\min }$ & $500 \times 10^{3} \mathrm{~m}$ \\
$H$ & Hydrostatic equilibrium crustal thickness & $10-60 \times 10^{3} \mathrm{~m}$ \\
& & $25-40 \times 10^{3} \mathrm{~m}$ \\
$H_{\min }$ & Lowest value for $\alpha_{\min }$ & $25 \times 10^{3} \mathrm{~m}$ \\
$H_{\max }$ & Highest value for $\alpha_{\max }$ & $40 \times 10^{3} \mathrm{~m}$ \\
$z$ & GOCE satellite altitude & $250 \times 10^{3} \mathrm{~m}$ \\
$\alpha$ & Degree of compensation & \\
$\beta$ & Ratio between GOCE gradients and its topographic contribution & \\
\hline
\end{tabular}

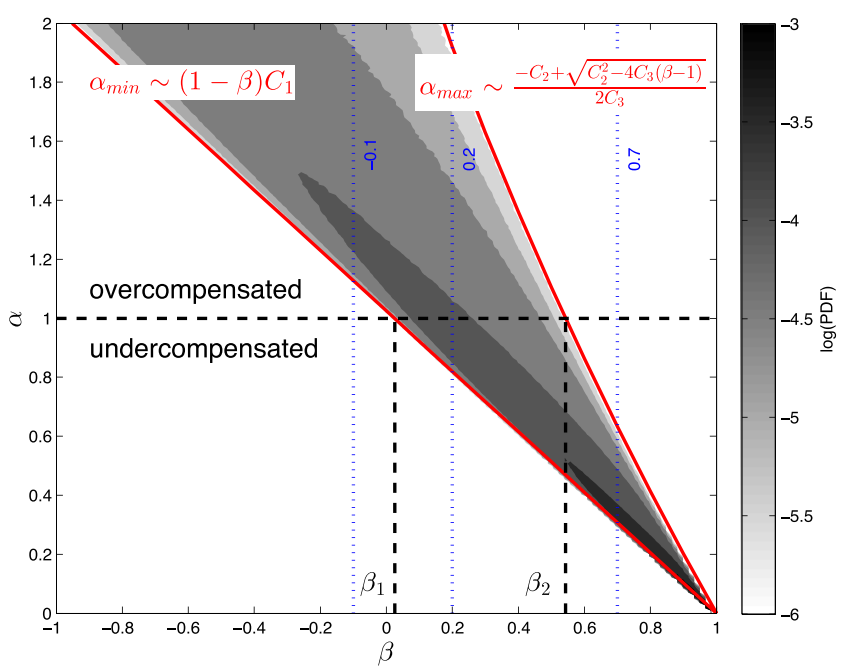

Figure 3. Relationship between the degree of compensation $\alpha$ and the ratio $\beta$. The grey colour scale gives the probability density associated with a collection of $10^{8}$ models. Red lines give the lower and the upper bounds $\left(\alpha_{\min }\right.$ and $\left.\alpha_{\max }\right)$ for the degree of compensation. Independently of the model parameter values, the topography is systematically overcompensated (respectively, undercompensated) for ratio values of $\beta<0.02$ (respectively, $\beta>0.55$ ). The blue dotted lines give the location of profiles presented in Fig. 5.

correspond to continental regions (Table 1); each parameter set then corresponds to a $(\alpha, \beta)$ couple. We sample the potential combinations of this six-parameter space by randomly selecting $10^{8}$ possible models using a uniform distribution for each parameter sampled from its a priori range (Table 1). This random selection is large enough to provide a quasi-systematic exploration of the parameter space with the associated $(\alpha, \beta)$ couples. The sample of $10^{8}(\alpha, \beta)$ couples is then analysed using a bivariate frequency histogram to derive a non-parametric statistical distribution, or probability density function (PDF), that describes the probability of occurrence of possible $(\alpha, \beta)$ couples for our a priori range of parameters.

The obtained PDF exhibits a clear relationship between the compensation degree $\alpha$ and gravity gradient ratio $\beta$ (Fig. 3). Unsurprisingly, $\alpha$ and $\beta$ are inversely correlated. A high degree of compen- sation involves a large-mass deficit at depth, which directly reduces the amplitude of the radial component $T_{z z}$. More interestingly, our calculations show that the lowest $\alpha$ values are bounded by a linear relationship between $\alpha$ and $\beta$, which corresponds to the lowest $(h, H)$ and the highest $R$ :

$\alpha_{\min } \sim(1-\beta) C_{1}$

In contrast, the upper bound for $\alpha$ is given by a non-linear relationship with $\beta$, which corresponds to the highest $\left(h, H, \rho_{c},|\Delta \rho|\right)$ and the lowest $R$ :

$\alpha_{\max } \sim \frac{-C_{2}+\sqrt{C_{2}^{2}-4 C_{3}(\beta-1)}}{2 C_{3}}$.

Derivations of eqs (8) and (9), and constants $C_{1}, C_{2}$ and $C_{3}$ are given in Appendix. Using the parameter ranges given in Table 1, the topography is overcompensated $(\alpha>1)$ for $\beta<0.02$, whereas $\beta>$ 0.55 is associated with an undercompensated $(\alpha<1)$ topography (Fig. 3).

We test the influence of each individual parameter by varying their value independently from the others, so that all the topographic deformations observed on the Earth's surface, in terms of amplitude, spatial extent and density contrasts, are considered. Fig. 4 shows how the relationships between $\alpha$ and $\beta$ associated with eqs (8) and (9) evolve as functions of $\rho_{c}, \Delta \rho, h, R, H$ and $z . \alpha_{\min }$ varies only slightly and is mainly influenced by the highest $R$ and the lowest $H$. In contrast, $\alpha_{\max }$ is much more sensitive to parameter values, especially to the highest $h, H$ and $\Delta \rho$. The sensitivity is weaker with the lowest $R$ and $z$. Both relationships are weakly dependent on $\rho_{c}$.

In order to estimate a degree of compensation $\alpha$ for a given ratio $\beta$ (derived from GOCE and topography data), we calculate likelihood distributions of $\alpha$ for all values of $\beta$ (discretized every 0.01 ) on the basis of their joint probability distribution (Fig. 3). Fig. 5 shows examples of such $\alpha$ likelihood distributions for three $\beta$ values. These distributions can be characterized by a maximum and half-width (values at $\frac{1}{2}$ maximum probabilities, Fig. 5), which are used in the following to quantify the degree of compensation $\alpha$ by its most-likely value and an associated uncertainty $\left(\alpha, \alpha_{l}\right.$ and $\alpha_{u}$; Fig. 6). 

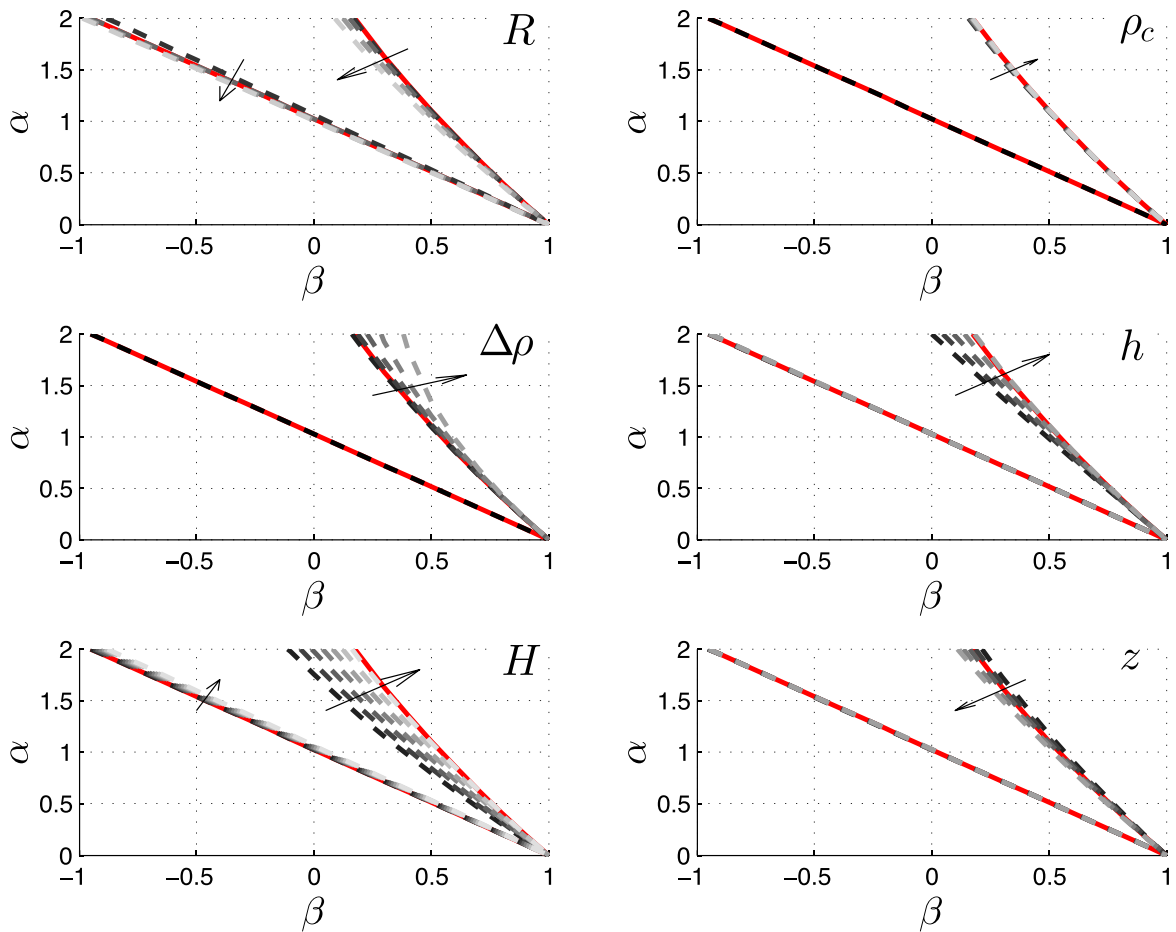

Figure 4. Sensitivity of the compensation degree $\left(\alpha_{\max }\right.$ and $\left.\alpha_{\min }\right)$ to model parameters. Parameters set: cylinder radius $R$, crustal density $\rho_{c}$, crust-mantle density contrast $\Delta \rho$, elevation $h$, reference crustal thickness $H$ and satellite elevation $z$. Parameter ranges: $R_{\min } \in[25 ; 100 \mathrm{~km}], R_{\max } \in[250 ; 1000 \mathrm{~km}]$, $\rho_{c} \in\left[2600 ; 2900 \mathrm{~kg} \mathrm{~m}^{-3}\right], \Delta \rho \in\left[-700 ;-300 \mathrm{~kg} \mathrm{~m}^{-3}\right], h_{\min } \in[0 ; 1 \mathrm{~km}], h_{\max } \in[1 ; 5 \mathrm{~km}], H_{\min } \in[10 ; 25 \mathrm{~km}], H_{\max } \in[30 ; 60 \mathrm{~km}]$ and $z \in[230 ; 270 \mathrm{~km}]$. The grey colour scale (dashed lines) and associated black arrows indicate an increase in the parameter value. The red lines are associated with the data collection presented in Fig. 3.

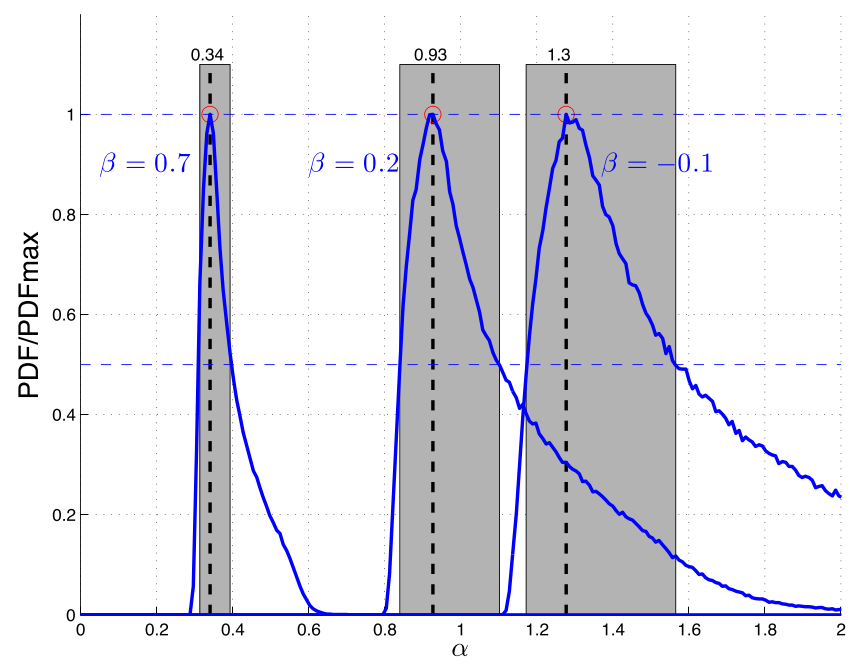

Figure 5. Example of probability density of $\alpha$ for three different values of $\beta$ (cf. Fig. 3). The red circles correspond to the obtained maximum. The most likely value of 'alpha' is given by the number above the red circles. The grey areas represent the range of possible 'alpha' values (uncertainty) for a selected threshold of 50 per cent probability.

\section{APPLICATION TO THE}

\section{ALASKA-CANADA CORDILLERA}

\subsection{Elevation, crust thickness and isostatic state}

On the basis of its first-order topography and geology, we can subdivide the NW America orogen area into three domains: (1) the Yakutat collision zone, (2) the Yukon Plateau and (3) the Northwest

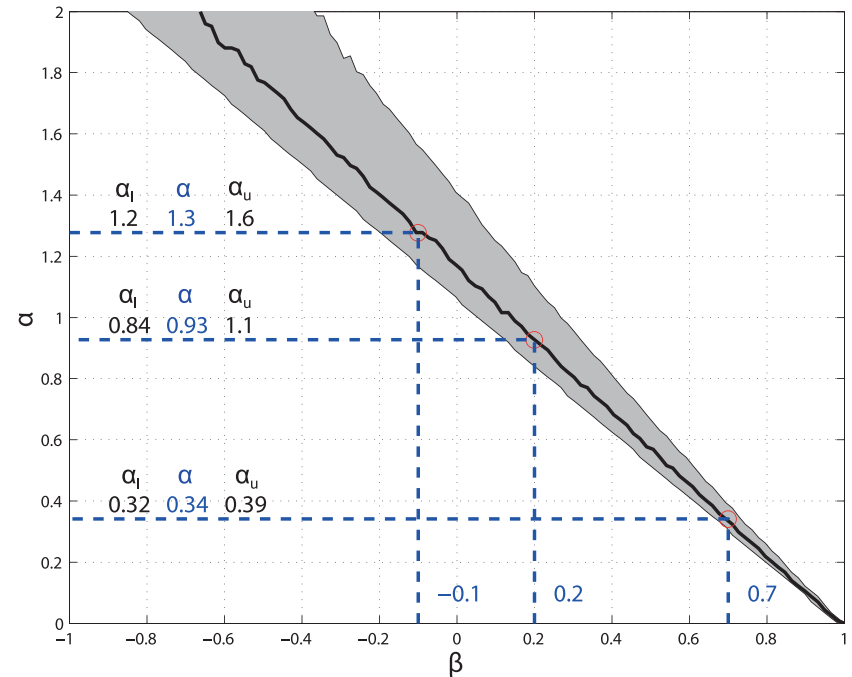

Figure 6. Transfer function between $\beta$ and $\alpha$. Black is the most likely $\alpha$. Grey envelop is associated with the $\alpha$ uncertainties. The red circles are associated with the three different values of $\beta$ presented Fig. 5. Blue text gives the value of $\beta$ and $\alpha$. Black text gives the lower $\left(\alpha_{l}\right)$ and upper $\left(\alpha_{u}\right)$ limit of $\alpha$.

Territories Craton (Fig. 1). The collision front, including the Alaska Range and the St Elias-Chugach-Wrangell Mountains, comprises high and steep mountains located at the northern boundary of the Yakutat block (Fig. 1) and is associated with an intense seismicity (Doser \& Lomas 2000; Mazzotti et al. 2008). The average elevation in this region is $\sim 2500 \mathrm{~m}$, with highs up to $6000 \mathrm{~m}$ in the Alaska Range and St Elias Mountains. These ranges are inferred to result 
from a series of subduction and collision processes, including the present-day underthrusting of the Yakutat block. The crustal thickness is not well resolved for a large part of this area. Nevertheless, the isostatic anomaly map established by Barnes et al. (1994) shows that this region is not in Airy-Heiskanen equilibrium and the topography is undercompensated. A deep support related to the mantle dynamics around the edge of the Pacific slab could be expected in such context (Mazzotti et al. 2008).

The Yukon Plateau has an average elevation of $\sim 1000 \mathrm{~m}$ with little relief (Fig. 1) and a consistent crustal thickness of $\sim 35 \mathrm{~km}$ (Erdmer et al. 2001; Rasendra et al. 2014). At its easternmost part, it is delimited by the Mackenzie Mountains, which rise to an elevation of $\sim 2000 \mathrm{~m}$. Although located $600-800 \mathrm{~km}$ northeast of the Yakutat collision, these mountains are affected by a strong seismicity and mark the transition between the backarc active Cordillera and the stable Canadian Shield (Mazzotti et al. 2008). Strain transfer across the whole Cordillera is made possible by a hot lithosphere (Mazzotti \& Hyndman 2002). Isostatic equilibrium prevails for most of this region (Lewis et al. 2003).

Finally, lowlands and lakes, with an average elevation of $\sim 300 \mathrm{~m}$ and a crust of $35 \mathrm{~km}$ thickness (Cook et al. 1999), characterize the Northwest Territories Craton (Fig. 1). This region is associated with a cold and thick lithosphere, similar to the Canadian Shield, which contributes to the regional isostatic equilibrium (Lewis et al. 2003).

\subsection{GOCE results}

The GOCE radial gravity gradient $T_{z z}$ over the Alaska-Canada Cordillera reflects at first order the topography (Figs 7a and b). The radial gradient displays a significant signal over the topography highs with a maximal magnitude of $0.8 \mathrm{E}$ in the St. Elias-Wrangell Mountains. Minimal values are observed over the eastern lowlands where the signal varies slowly. The Mackenzie Mountains, which culminate at $\sim 2000 \mathrm{~m}$, are associated with the higher signal in the Yukon plateau region.

We show the calculated topography gradient $T_{z z_{\text {topo }}}$ in Fig. 7(c). $T_{z z_{\text {topo }}}$ displays a pattern close to GOCE observations but with higher amplitudes ( $c f$. maximal of 2.6 E over the St Elias-Wrangell Mountains). This significant difference in amplitudes between observations and predictions points out the existence of a process reducing the gravitational effect of topography, such as local isostatic compensation by crustal thickness variations, which we can assess simply and efficiently by estimating a degree of compensation. Fig. 7(d) shows the spatial distribution of the gravity gradient ratio $\beta$. We distinguish the three different domains: the eastern lowlands with $\beta<$ -0.3 , the Yukon Plateau with $-0.3 \leq \beta \leq 0.3$ and the northwest highlands with $\beta>0.3$.

The corresponding degree of compensation is obtained from the transfer function between $\beta$ and $\alpha$ established in Section 2.2.3 and is shown in Fig. 8. The transfer function is adapted to our study area using a priori information available on the reference crustal thickness $H$ (Table 1). The uncertainty range of the degree of compensation, $\alpha_{l}$ and $\alpha_{u}$ (Fig. 6), is represented in Figs 8(c) and (d). The three maps show a gradual increase of the degree of compensation under the Airy-Heiskanen hypothesis from the collision front to the stable craton area. $\alpha$ is significantly higher than 1 in the Eastern lowlands, indicating that the region is overcompensated. The Yukon Plateau area, characterized by $\alpha$ values varying between 0.7 and 1.2 , is close to the isostatic equilibrium. Finally, associated with $\alpha<0.7$, topography highs in the Alaskan forearc and Yakutat collision zone are only partially compensated.

\subsection{Discussion}

In order to validate the approach, we ensure the consistency between our results deduced from GOCE observations and the isostatic gravity anomalies derived from the WGM2012 global model based on terrestrial measurements and GRACE satellite data (Bonvalot et al. 2012). These isostatic anomalies are obtained by subtracting to the Earth Gravitational Model 2008 (EGM2008; Pavlis et al. 2008) the gravitational effect of the topography and its low-density root according to the Airy-Heiskanen model with a reference crust thickness of $30 \mathrm{~km}$. Thus, a negative (positive) isostatic anomaly indicates an over (under) compensation of reliefs whereas a zero isostatic anomaly reflects a topography perfectly compensated.

We first apply a $200 \mathrm{~km}$ high-pass filter to WGM2012 isostatic anomalies to obtain a similar wavelength content as for our satellitebased analysis. Second, we correct the WGM2012 isostatic anomaly to account for the difference in crustal thickness reference $(30 \mathrm{~km}$ for WGM2012 versus $35 \mathrm{~km}$ in our analysis tuned to regional seismic data). This correction, calculated using eqs (2) and (4) to account for topography variations, corresponds to about $0-10 \mathrm{mGal}$ depending on local topography. The resulting WGM2012 isostatic anomaly shows a good general agreement with the degree of compensation derived from GOCE observations (Fig. 9 versus Fig. 8). Both our GOCE-based results and the ground-based WGM2012 isostatic anomaly show that Airy-Heiskanen isostasy prevails for the Yukon Plateau whereas additional mechanisms are required to support topography below the Northwest Territories Craton and the Yakutat collision zone.

For the Northwest Territories region, our analysis and the isostatic anomaly map indicate an overcompensated topography, that is, that the actual crustal root is greater than the isostatic root predicted by the Airy-Heiskanen model (Figs 8 and 9). However, seismic data indicate that crustal thickness under this region is similar to that of the Yukon Plateau ( $\sim 33-35 \mathrm{~km}$; Cook et al. 1999; Erdmer et al. 2001; Rasendra et al. 2014) and corresponds to isostatic equilibrium with the Plateau elevation $(\sim 1 \mathrm{~km})$. Thus, the overcompensated signature and the support of the low topography are not associated with simple Airy-Heiskanen isostasy. As shown by Lewis et al. (2003) and Hasterok \& Chapman (2007), thermal isostasy is likely the primary support mechanism due to the presence of a thick and cold lithosphere below the Craton. Near-sea level elevation regions (0-200 $\mathrm{m})$, such as the Canadian Craton, have indeed a wide range of crustal thicknesses $(25-55 \mathrm{~km})$ and a simple relation between these two quantities is difficult to establish (Zoback \& Mooney 2003). This implies a significant contribution of a cooler and denser lithospheric mantle to reach the isostatic equilibrium in these areas.

In contrast with the Craton, the Yakutat collision system to the west is isostatically undercompensated: crustal thickening resulting from the collision between the Yakutat block and the American continent does not completely compensate the St Elias and Chugach Mountains elevation (Figs 8 and 9). Our approach indicates the existence of additional mechanisms that support the topography in the collision zone: (1) the continental lithosphere could be rigid enough to partially maintain these reliefs. However, the collision zone is characterized by large deformation and faults, which can highly reduce the rigidity of lithosphere, as shown by the low effective elastic thickness $(<20 \mathrm{~km})$ obtained over the region (Kirby \& Swain 2009). Moreover, the Alaska-Canada Cordillera is located in a recent backarc region characterized by a hot, thin and weak lithosphere (Hyndman et al. 2005). (2) Alternatively, asthenospheric mantle dynamic processes could contribute to topography support, such as sublithospheric erosion by small-scale convection (Cadio 

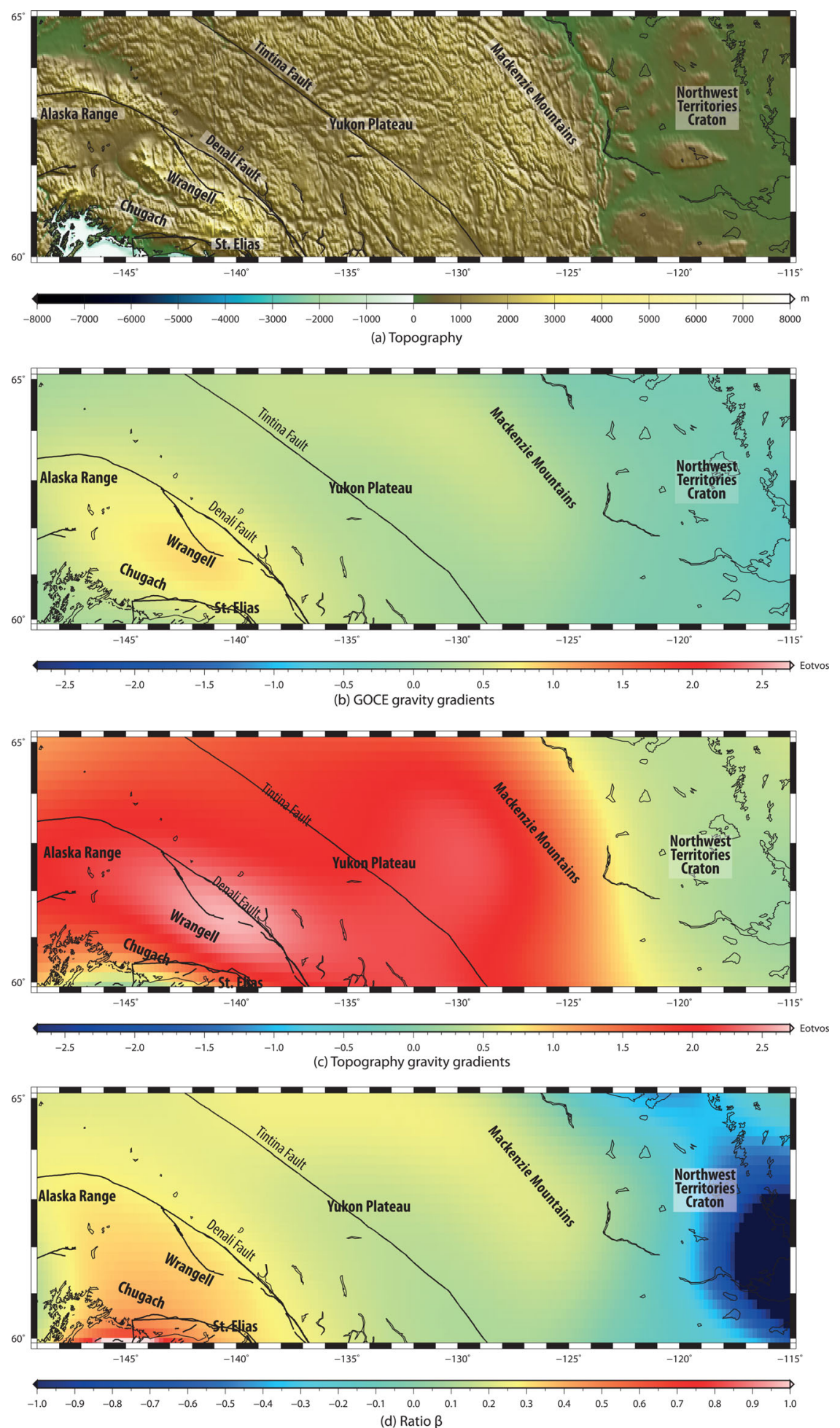

Figure 7. (a) Topography, (b) the GOCE radial gravity gradient $T_{z z}$, (c) the uncompensated topographic contribution $T_{z z}$ topo and (d) the ratio $\beta$ over the Alaska-Canada Cordillera.

et al. 2012). Mantle flow associated with the edge of the Yakutat slab could also contribute to dynamic topography. Thus, our approach could allow the identification of dynamic topography in this region and provide an estimate of its minimal contribution. The comparison between observed and synthetic gravity gradients derived from numerical modeling of subduction process could bring further constraints on the slab dynamics at the collision front.

\section{CONCLUSIONS}

The approach developed here evaluates the degree of the local isostatic compensation of the topography, under the Airy-Heiskanen hypothesis, in continental region. This simple method only requires knowledge of the radial GOCE gradient and its topographic contribution, data available on the entire Earth's surface. Consequently, our approach can be easily applied to any continental region and 

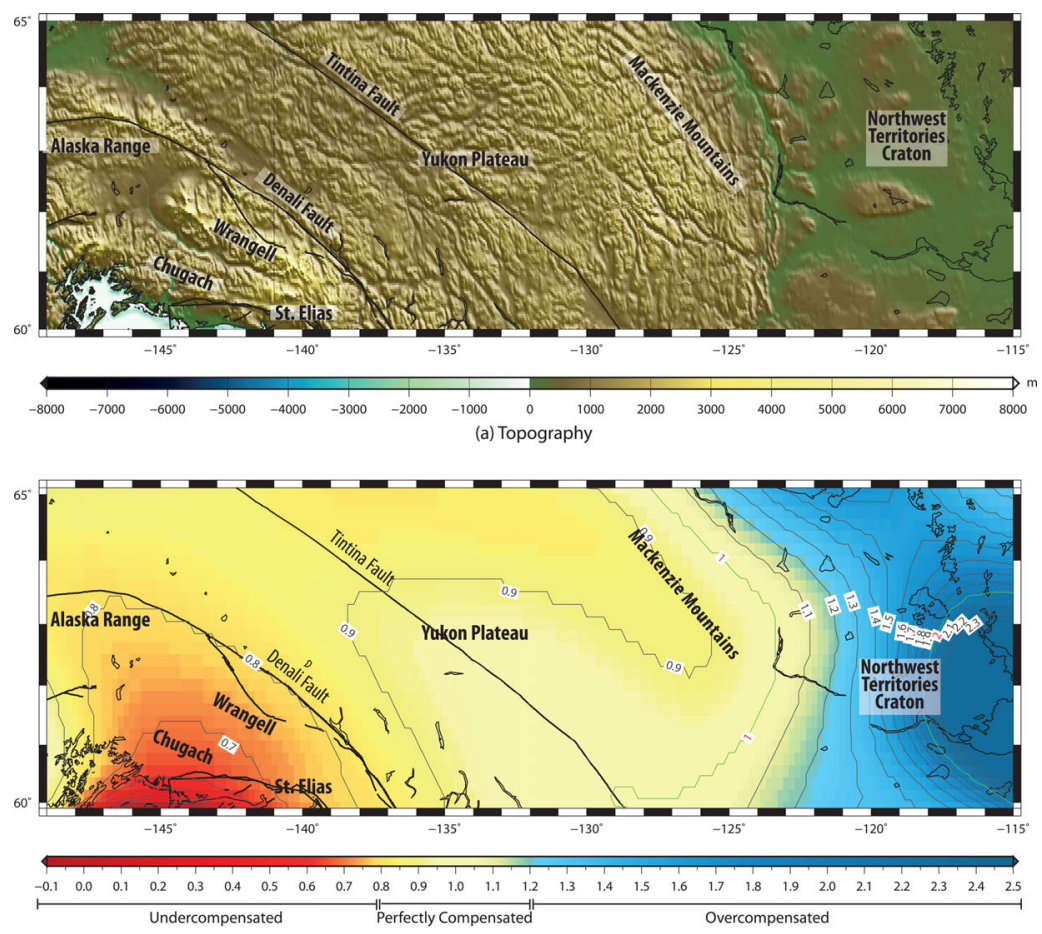

(b) $a$
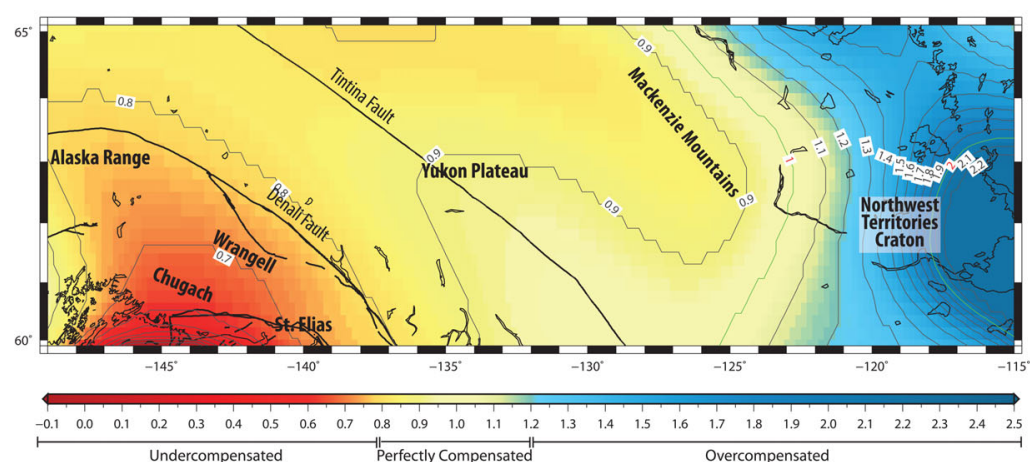

(c) $a_{1}$
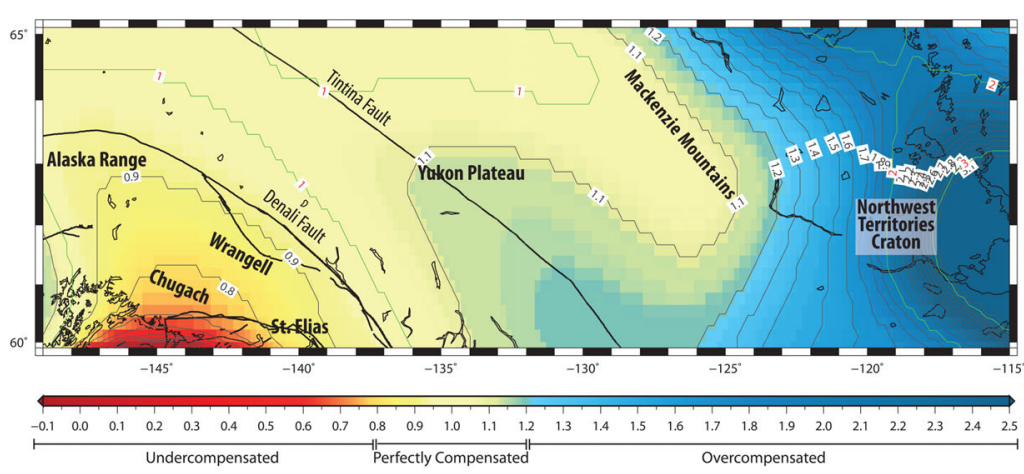

(d) $a_{u}$

Figure 8. (a) Topography, (b) the degree of compensation $\alpha$ and (c) its estimated range $\alpha_{l}$ and (d) $\alpha_{u}$ over the Alaska-Canada Cordillera.

can integrate independent constraints on parameters specific to each region. It can be also adapted to oceanic domain, allowing the study of subduction zones. Finally, the gravity gradient tensor holds complementary information in other components, which can be used in future studies.

Our application on the NW America orogen confirms the presence of additional mechanisms in the topography support, involv- ing thermal isostasy, lithosphere rigidity and probably mantle dynamics. This approach provides constraints on the maximal (minimal) potential isostatic (dynamic) topography and associated with independent data (seismic velocity, seismicity, surface heat flow, etc.) can bring additional information on the Moho depth, on thermal or mechanical lithospheric variations, and on deeper mantle processes. 


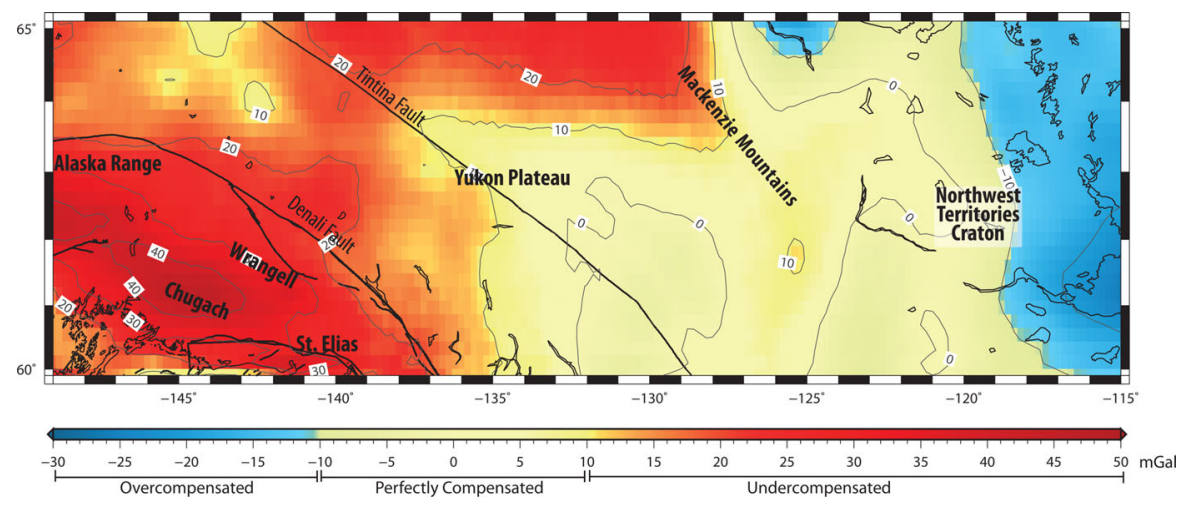

Figure 9. Isostatic gravity anomalies derived from the WGM2012 global model (Bonvalot et al. 2012) smoothed with a $200 \mathrm{~km}$ high-pass filter and corrected to account for the difference in crustal thickness reference ( $30 \mathrm{~km}$ for WGM2012 versus $35 \mathrm{~km}$ in our analysis tuned to regional seismic data).

\section{ACKNOWLEDGEMENTS}

We are grateful to two anonymous reviewers for critical and constructive comments on the manuscript. This study was supported by French 'Agence Nationale de la Recherche' grant ANR-12CHEX-0004-01 (DefDyCor) and by the 'Centre National d'Etudes Spatiales' (CNES-TOSCA science committee). We wish to thank Elisa Dagnaud for her assistance in administration.

\section{REFERENCES}

Álvarez, O., Gimenez, M., Braitenberg, C. \& Folguera, A., 2012. GOCE satellite derived gravity and gravity gradient corrected for topographic effect in the South Central Andes region, Geophys. J. Int., 190(2), 941959.

Barnes, D.F., Mariano, J., Morin, R.L., Roberts, C.W. \& Jachens, R.C., 1994 Incomplete isostatic gravity map of Alaska, in The Geology of Alaska, Vol. G-1 ( plate 9, scale 1:2 500 000), eds Plafker, G. \& Berg, H.D., Geological Society of America, Geology of North America.

Bonvalot, S. et al., 2012. World Gravity Map, Commission for the Geological Map of the World. BGI-CGMW-CNES-IRD, Paris.

Bouman, J. et al., 2015. GOCE gravity gradient data for lithospheric modeling, Int. J. Appl. Earth Obs., 35(A), 16-30.

Bouman, J., Ebbing, J., Fuchs, M., Sebera, J., Lieb, V., Szwillus, W., Haagmans, R. \& Novak, P., 2016. Satellite gravity gradient grids for geophysics, Sci. Rep., 6, 21050, doi:10.1038/srep21050.

Braun, J., 2010. The many surface expressions of mantle dynamics, Nat. Geosci., 3, 825-833.

Bruinsma, S.L., Förste, C., Abrikosov, O., Lemoine, J.-M., Marty, J.-C., Mulet, S., Rio, M.-H. \& Bonvalot, S., 2014. ESA's satellite-only gravity field model via the direct approach based on all GOCE data, Geophys. Res. Lett., 41, 7508-7514.

Cadio, C., Ballmer, M., Panet, I., Diament, M. \& Ribe, N., 2012. New constraints on the origin of the Hawaiian swell from wavelet analysis of the geoid to topography ratio, Earth planet. Sci. Lett., 359-360, 40-54.

Chase, C.G., Libarkin, J.A. \& Sussman, A.J., 2002. Colorado Plateau: geoid and means of isostatic support, Int. Geol. Rev., 44, 575-587.

Cook, F.A., van der Velden, A.J. \& Hall, K.W., 1999. Frozen subduction in Canada's Northwest Territories: lithoprobe deep lithospheric reflection profiling of the western Canadian shield, Tectonics, 18, 1-24.

Doser, D.I. \& Lomas, R., 2000. The transition from strike-slip faulting to oblique subduction in southeastern Alaska from seismological studies, Tectonophysics, 316, 45-65.

Drinkwater, M.R., Floberghagen, R., Haagmans, R., Muzi, D. \& Popescu, A., 2003. GOCE: ESA's first Earth Explorer Core mission, in Earth Gravity Field From Space: From Sensors to Earth Sciences, Space Sci. Ser. ISSI, Vol. 17, pp. 419-432, eds Beutler, G.B. et al., Kluwer.

Erdmer, P., Cook, F., Clowes, R., Snyder, D., Evenchick, C., van der Velden, A. \& Hall, K., 2001. Some geological constraints on Cordilleran structure imposed by Line 3 reflections-MacMillan Pass to White Pass, in SlaveNorthern Cordillera Lithospheric Evolution Transect and Cordilleran
Tectonics Workshop, Lithoprobe Report 79, pp. 54-55, Compilers Cook, F. \& Erdmer, P.

Flament, N., Gurnis, M. \& Müller, R.D., 2013. A review of observations and models of dynamic topography, Lithosphere, 5, 189-210.

Fuchs, M. \& Bouman, J., 2011. Rotation of GOCE gravity gradients to local frames, Geophys. J. Int., 187, 743-753.

Grombein, T., Seitz, K. \& Heck, B., 2013. Optimized formulas for the gravitational field of a tesseroid, J. Geodesy, 87(7), 645-660.

Grombein, T., Luo, X., Seitz, K. \& Heck, B., 2014. A wavelet based assessment of topographic isostatic reductions for GOCE gravity gradients, Surv. Geophys., 35(4), 959-982.

Hager, B., Clayton, C., Richards, M., Comer, R. \& Dziewonski, A., 1985. Lower mantle heterogeneity, dynamic topography and the geoid, Nature, 313, 541-545.

Hasterok, D. \& Chapman, D.S., 2007. Continental thermal isostasy: 2. Application to North America, J. geophys. Res., 112, B06415, doi:10.1029/2006JB004664.

Hirt, C., Kuhn, M., Featherstone, W.E. \& Göttl, F., 2012. Topographic/isostatic evaluation of new-generation GOCE gravity field models, J. geophys. Res., 117, B05407, doi:10.1029/2011JB008878.

Hyndman, R.D., Currie, C.A. \& Mazzotti, S., 2005. Subduction zone backarcs, mobile belts, and orogenic heat, GSA Today, 15(2), doi:10:1130/1052-5173.

Kirby, J. \& Swain, C., 2009. A reassessment of spectral TE estimation in continental interiors: the case of north america, J. geophys. Res., 114(B8), 1978-2012.

Lahr, J.C. \& Plafker, G., 1980. Holocene Pacific-North America plate interaction in southern Alaska: implications for the Yakataga seismic gap, Geology, 8, 483-486.

Lewis, T.J., Hyndman, R.D. \& Flück, P., 2003. Heat flow, heat generation, and crustal temperatures in the northern Canadian Cordillera: thermal control of tectonics, J. geophys. Res., 108(B6), doi:10.1029/2002JB002090.

Mariani, P., Braitenberg, C. \& Ussami, N., 2013. Explaining the thick crust in paraná basin, brazil, with satellite GOCE gravity observations, J. South Am. Earth Sci., 45, 209-223.

Mazzotti, S. \& Hyndman, R.D., 2002. Yakutat collision and strain transfer across the northern Canadian Cordillera, Geology, 30, 495-498.

Mazzotti, S., Leonard, L.J., Hyndman, R.D. \& Cassidy, J.F., 2008. Tectonics, dynamics, and seismic hazard in the Canada-Alaska cordillera, in Active Tectonics and Seismic Potential of Alaska, Vol. 179, pp. 297-319, eds Freymueller, J.T., Haeussler, P.J., Wesson, R.L. \& Ekstrom, G., Geophys. Monograph Series, American Geophysical Union.

Mikhailov, V., Pajot, G., Diament, M. \& Price, A., 2007. Tensor deconvolution: a method to locate equivalent sources from full tensor gravity data, Geophysics, 72(5), 61-69.

Panet, I., Pajot-Metivier, G., Greff-Lefftz, M., Métivier, L., Diament, M. \& Mandea, M., 2014. Mapping the mass distribution of Earth's mantle using satellite-derived gravity gradients, Nat. Geosci., 7, 131-135.

Pavlis, N.K., Factor, J.F. \& Holmes, S.A., 2007. Terrain-related gravimetric quantities computed for the next EGM, in Proceedings of 1 st international symposium of the IGFS: Gravity Field of the Earth, Special Issue, Vol. 18, pp. 318-323. 
Pavlis, N.K., Holmes, S.A., Kenyon, S.C. \& Factor, J.F., 2008. An earth gravitational model to degree 2160, in EGU General Assembly 2008 (EGM'08), Vienna, Austria, April 13-18.

Plafker, G., Moore, J.C. \& Winkler, G.R., 1994. Geology of the southern Alaska margin, in The Geology of Alaska, Vol. G1, pp. 389-449, eds Plafker, G. \& Berg, H.C., Geological Society of America, Geology of North America.

Rasendra, N., Bonnin, M., Mazzotti, S. \& Tiberi, C., 2014. Crustal and upper mantle anisotropy related to fossilized transpression fabric along the Denali Fault, northern Canadian Cordillera, Bull. seism. Soc. Am., 104(4), 1964-1975.

Reguzzoni, M., Sampietro, D. \& Sansò, F., 2013. Global Moho from the combination of the CRUST 2.0 model and GOCE data, Geophys. J. Int., $195,222-237$.
Rummel, R., Yi, W. \& Stummer, C., 2011. GOCE gravitational gradiometry, J. Geod., 85, 777-790.

Shin, Y.H. et al., 2015. Moho topography, ranges and folds of Tibet by analysis of global gravity models and GOCE data, Sci. Rep., 5, 11681, doi:10.1038/srep11681.

Tapley, B. et al., 2005. GGM02 - an improved Earth gravity model from GRACE, J. Geod., 79, 467-478.

Turcotte, D. \& Schubert, G., 2002. Geodynamics, 2nd edn, Cambridge Univ. Press.

Watts, A.B., 2001. Isostasy and Flexure of the Lithosphere, Cambridge Univ. Press.

Zoback, M.-L. \& Mooney, W.D., 2003. Lithospheric buoyancy and continental intraplate stresses, Int. Geol. Rev., 45, 95118.

\section{APPENDIX: MATHEMATICAL FORMULATIONS BETWEEN $\alpha$ AND $\beta$}

Using the function of real $f(x)=\frac{x}{\sqrt{x^{2}+R^{2}}}$ eq. (6) can be written as

$$
\begin{aligned}
T_{z z_{\text {topo }}} & =2 \pi G \rho_{c}(f(z)-f(z+h)) \\
T_{z z_{\text {crustal root }}} & =2 \pi G \Delta \rho(f(z+h+H)-f(z+h+H+b)) .
\end{aligned}
$$

The function $f$ being infinitely differentiable, it can be approximated by using a finite number of terms of its Taylor series with $(x, y) \in \mathbb{R}^{2}$ :

$f(x+y)=f(x)+y f^{\prime}(x)+\frac{y^{2}}{2 !} f^{\prime \prime}(x)+\cdots+\frac{y^{n}}{n !} f^{(n)}(x)+\cdots$

Compared to $z, H$ and $R$ the elevation $h$ is always small. Hence, two cases can be considered to simplified eq. (7). First assuming that the crustal root $b$ is also small the first two terms of eq. (A2) can be used to simplify eqs (6) and (7)

$T_{z z_{\text {topo }}} \sim-2 \pi G \rho_{c} h R^{2}\left(z^{2}+R^{2}\right)^{-\frac{3}{2}}$

$T_{z z_{\text {crustal root }}} \sim 2 \pi G \Delta \rho h R^{2}\left((z+h+H)^{2}+R^{2}\right)^{-\frac{3}{2}}$.

The ratio $\beta$ between the observed gravity gradient $T_{z z}$ and $T_{z z_{\text {topo }}}$ is then

$\beta=\frac{T_{z z}}{T_{z z \text { topo }}}=\frac{T_{z z_{\text {topo }}}+T_{z z_{\text {crustal root }}}}{T_{z z_{\text {topo }}}}=1+\frac{T_{z z_{\text {crustal root }}}}{T_{z z_{\text {topo }}}} \sim 1-\alpha\left(\frac{z^{2}+R^{2}}{(z+h+H)^{2}+R^{2}}\right)^{\frac{3}{2}}$

which corresponds to a simple linear relationship between $\beta$ and $\alpha$

$\alpha \sim(1-\beta) C_{1}$

$C_{1}=\left(\frac{z^{2}+R^{2}}{(z+h+H)^{2}+R^{2}}\right)^{-\frac{3}{2}}$.

This equation can be used for small $b$ only. Thus, it gives a lower bound for $\alpha$. Note that for $\lim _{R \rightarrow+\infty}(\alpha)=1-\beta$.

For cases in which the crustal root $b$ is comparable to $z, H$ or $R$, the third terms of eq. (A2) cannot be neglected and $T_{z z_{\text {crustal root }}}$ becomes

$T_{z z_{\text {crustal root }}} \sim 2 \pi G \Delta \rho\left[-b R^{2}\left((z+h+H)^{2}+R^{2}\right)^{-\frac{3}{2}}+3 \frac{b^{2}}{2} R^{2}(z+h+H)\left((z+h+H)^{2}+R^{2}\right)^{-\frac{5}{2}}\right]$.

The ratio $\beta$ is then

$\beta \sim 1-C_{2} \alpha-C_{3} \alpha^{2}$

$C_{2}=\left(\frac{z^{2}+R^{2}}{(z+h+H)^{2}+R^{2}}\right)^{\frac{3}{2}}=\frac{1}{C_{1}}$

$C_{3}=\frac{3 \rho_{c}}{2 \Delta \rho} h(z+h+H) \frac{\left[(z+h+H)^{2}+R^{2}\right]^{-\frac{5}{2}}}{\left(z^{2}+R^{2}\right)^{-\frac{3}{2}}}$.

Thus, we obtain the following quadratic polynomial equation

$C_{3} \alpha^{2}+C_{2} \alpha+(\beta-1) \sim 0$

which has for $\operatorname{root}(\alpha>0)$

$\alpha \sim \frac{-C_{2}+\sqrt{C_{2}^{2}-4 C_{3}(\beta-1)}}{2 C_{3}}$. 